\title{
Impact of Industry 4.0 on Healthcare: A Systematic Literature Review (SLR) from the Last Decade
}

\author{
https://doi.org/10.3991/ijim.v15i18.25531 \\ Ishamuddin Mustapha ${ }^{1(\bowtie)}$, Nohman Khan ${ }^{2}$, Muhammad Imran Qureshi ${ }^{1}$, \\ Ahmad Ali Harasis ${ }^{3}$, Nguyen Thuy Van ${ }^{4}$ \\ ${ }^{1}$ Universiti Teknikal Malaysia, Melaka, Malaysia \\ ${ }^{2}$ UniKL Business School, Universiti Kuala Lumpur, Malaysia \\ ${ }^{3}$ Middle East University, Amman, Jordan \\ ${ }^{4}$ Universiti Teknologi Malaysia, Johor, Malaysia \\ Ishamuddin@unikl
}

\begin{abstract}
This study aims to analyze the impact of industry 4.0 on the healthcare system. Scopus database is used to extract the data, and 297 articles are initially found in the database. We used the PRISMA statement 2015 to include and exclude data; the final 48 articles were included for the review. The author's keyword and VOS viewer co-occurrence of the terms are classifying the same result. The records are presented in three major categories, and outcomes are discussed accordingly in the classification of literature. Healthcare systems, cloud computing digital technologies are the major research areas in industry 4.0 in the last decade. Healthcare is significantly improved due to the technologies and services influenced by industry 4.0. The findings of the study showing that industry 4.0 is enhancing standards of healthcare significantly. Industry 4.0 enables many new technologies, like blockchain, big data, cloud computing, and IoTs, to track patients' medical records. That more accessible for healthcare professionals to understand the patient's history and deal accordingly.
\end{abstract}

Keywords - industry 4.0, healthcare, digital health, systematic review

\section{$1 \quad$ Introduction}

The Industry Revolution 4.0 (IR 4.0) is the latest idea, covering the main technological advances in computerization, management, and information technologies used to manufacture processes. The health sector is considered one of the areas that are most vulnerable to technological development, so it is being affected by digitization, transforming the way healthcare is providing, from the communication between patients and healthcare providers to the government and the interested parties [1]. As the establishment tools grow, eHealth is next alongside. Therefore, the specific description of the term has experienced radical modifications and technical specifications, the latest available ones concerning the concept referred to as the industry 4.0. In its broader 
meaning, the concept of IR 4.0 can be viewed as an explicit legislative pledge to nurture a set of technology to enhance the overall progress [2]. According to [3], they are launching IR 4.0 concept established enormous possibilities for many industry sectors to enhance their processes.

Consequently, they can increase their productivity, cost efficiency, consistency, excellence, and suppleness. One crucial area that can efficiently take advantage of this concept is healthcare. Emerging requirements of healthcare worldwide demand efficient and effective medical services that can manage the requirements. Technologies enhance the abilities of traditional healthcare infrastructure worldwide, and digitalization is a prominent enabler in the current healthcare crisis [4]. Industry 4.0 enables many new technologies, like blockchain, big data, cloud computing, and IoTs, to track patients' medical records. That more accessible for the healthcare professionals to understand the patient's history and deal accordingly [5]. However, the COVID-19 pandemic challenges the healthcare robustness around the globe, and healthcare facilities are failed to perform. Developed and underdeveloped countries' healthcare is fully occupied during the pandemic. However, technological advancement plays a pivotal role during a disaster [6]. Healthcare professionals used the IR 4.0 technologies to test the suspects and control the transmission. Recent healthcare requirements lead to more efficient services that can provide medical services for distant residents and reduce the loads on the hospitals [7]. Healthcare applications also enhance medical awareness among the users, especially elderly patients who require more attention.

The current study aims to identify the impacts of Industry Revolution 4.0 (IR 4.0) on healthcare. The recent development and requirements for healthcare infrastructure and future technologies in the published research are analyzed in the current study. The current study included articles related to IR 4.0 and healthcare.

\section{$2 \quad$ Materials and methods}

During the reporting of the findings and the development of the research structure, authors worldwide use PRISMA statement 2015. The systematic literature review (SLR) is a manual to improve the reliability of the reviews and meta-analysis. The PRISMA statement guide describes the overall research procedure for picking and refusing articles in the systematic review. This SLR ground research is restricted to available information on industry 4.0 and healthcare systems-Scopus's database, applied for the literature mining. The keywords are used "industry 4.0 AND healthcare" in the search bar. The database's total results are 297, and the subject is selected for the current study engineering, computer science, medicine, social science, nursing, health professional, business, management and accounting, economics, econometrics, and finance. The subject selections shrink the results to 285 articles. Some critical inclusion and exclusion criteria for this review were published articles in English and industry 4.0 and healthcare. The review papers and articles are included in the review. Later, a careful screening was performed for each identified classification to determine relevant records, and only 48 studies were selected to be included to synthesize the review., Figure 1 shows the overall PRISMA statement 2015 selection and rejection process of the current study in detail. 


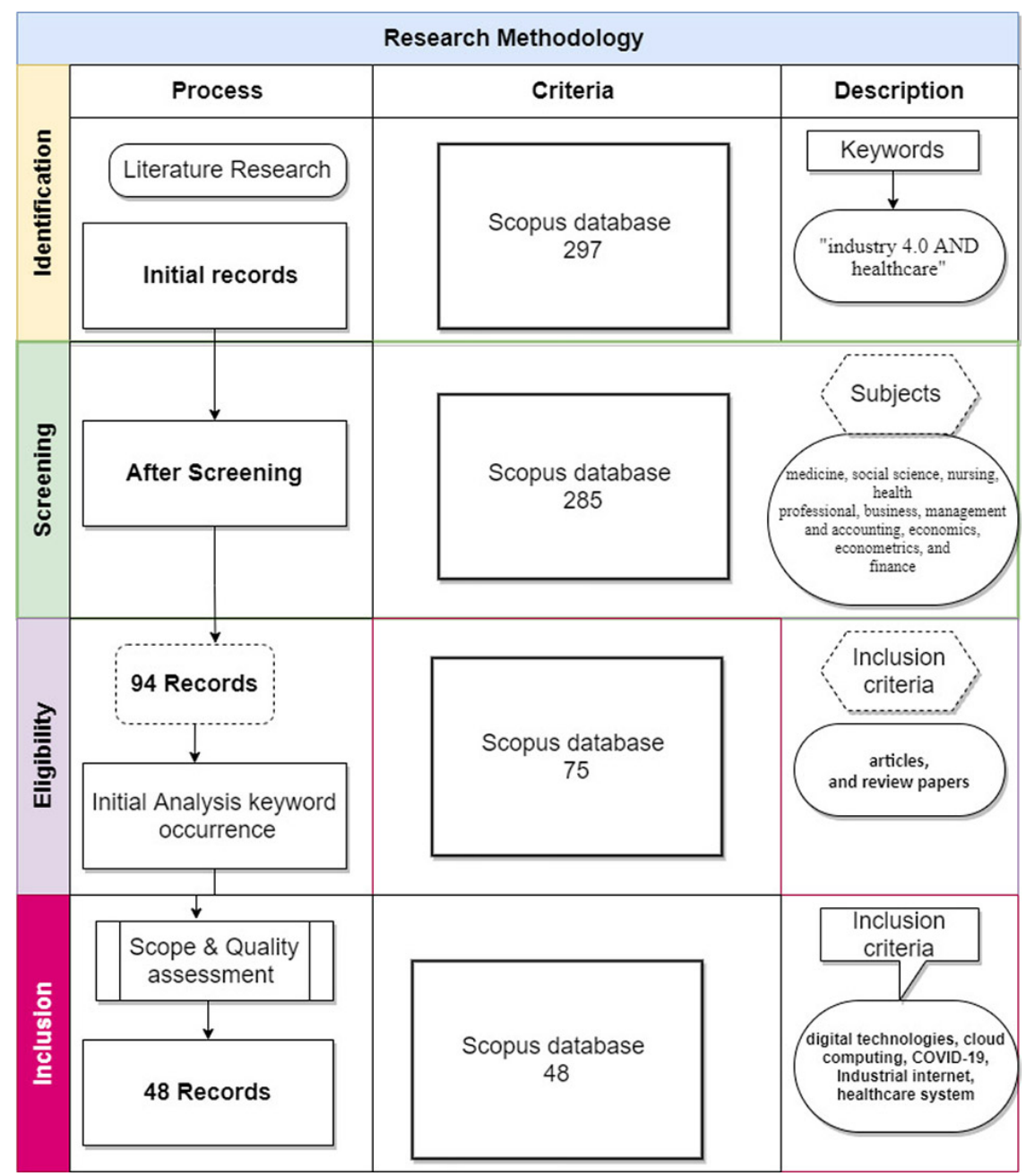

Fig. 1. Prisma statement 2015 for inclusion and exclusion criteria

\subsection{Studies included in qualitative synthesis}

Following the selection of the 48 papers, a two-step process was implemented. That begin, consistent metadata was introduced into Microsoft Excel to vividly analyze literature, such as the segment and settings of work done in the literature. The stage after that accepted content analysis to categorize and analyze key probe streams, report on recent studies across various themes, and highlight potential concerns and opportunities for future research. Content science is an interdisciplinary research method for analyzing papers and articles to describe and evaluate the apparent content of communications about specific groups using a systematic method that allows for replicated and valid results from texts. 


\subsection{Descriptive analysis}

Figure 2 depicts the multidisciplinary nature of the research question and highlights the contributions of various disciplines to Industry 4.0. Computer science is the most influential field, accounting for $18 \%$ of the studies included in the review. Engineering accounts for 16 percent of all studies, followed by Business, Management, and Accounting, accounting for 14 percent, Economics, Econometrics, and Finance, which accounts for $10 \%$ of all studies, and Social Sciences, which accounts for $10 \%$ of all studies. Figure 2 depicts the percentage contribution of the subject.

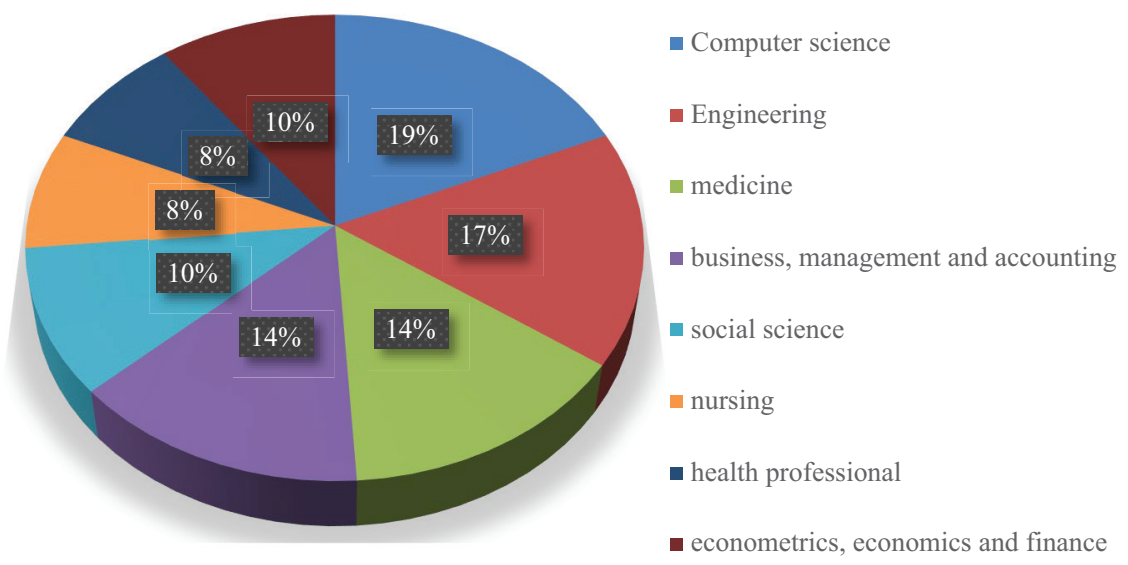

Fig. 2. The distribution of subjects

The current study focuses on the year that the articles were published instead of the period of the articles. The primary goal of the year-by-year division is to realize the number of publications chosen and meeting the article's standards in a specified year. Figure 3 depicts an example of the literary works from 2016 to 2021, year by year. The year 2020 aided the most people with 18 papers. Each one of the years 2019, 14, and 2018 contributed 11 studies. In 2021, three new studies were added. Figure 3 depicts comprehensive articles from various years.

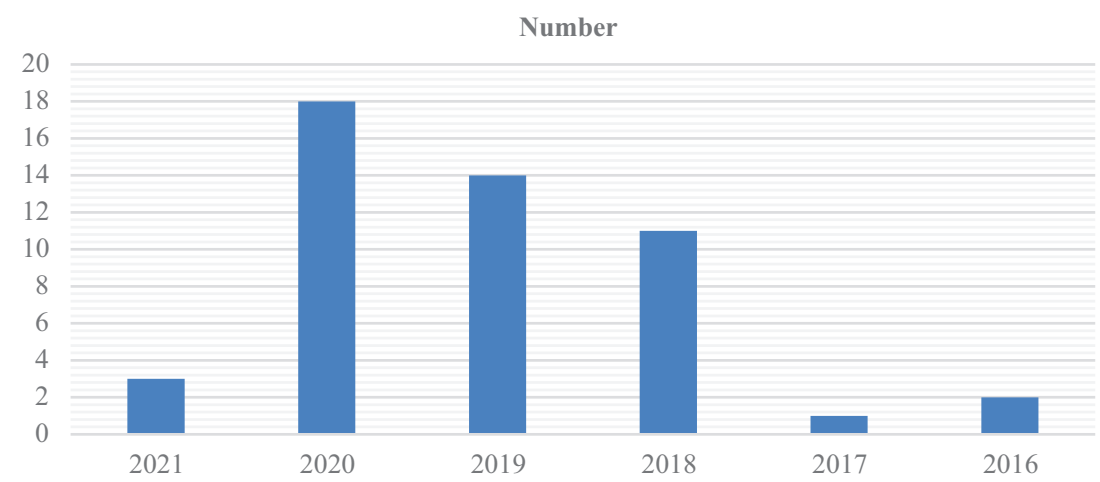

Fig. 3. Allocation of the published literature 
Furthermore, a journal-based publication analysis is performed for the current study, and it is discovered that IEEE Access contributes the most articles, with six articles. Second, most of the studies come from the Future Generation Computer Systems category, which has five articles in total. The titles of the previous studies are gradually removed from the current study. Future Generation Computer Systems has contributed two articles. Table 1 displays the source title information and a citation report displaying the results of the research article selected from each journal.

Table 1. Source's titles and citations

\begin{tabular}{|l|c|c|}
\hline \multicolumn{1}{|c|}{ Source Title } & Numbers & Citations \\
\hline IEEE Access & 6 & 125 \\
\hline IEEE Transactions on Industrial Informatics & 5 & 65 \\
\hline Future Generation Computer Systems & 2 & 66 \\
\hline IEEE Journal of Biomedical and Health Informatics & 2 & 32 \\
\hline Journal of Theoretical and Applied Information Technology & 2 & 34 \\
\hline
\end{tabular}

The documents were also subjected to content analysis to ascertain the study's classifications. VOS Viewer software analyses the content of published literature - data clusters generated on the text to cluster related ideas. The current study found that authors' terms and keywords defined further in the publications' indexing process detailed in the databases are perfectly appropriate for bibliometric analysis aiming to disclose the examining field's structure. As a result, we used both types of keywords for the co-occurrence analysis within the study region related to digital fintech services. The investigation had 48 records in total, with 179 keywords provided by the dataset. Only the most frequent 96 keywords occurring in a total of 10 documents were firmly defined and picked. The content analysis findings are depicted in Figure 4- the cluster is divided into three large clusters, depicted in distinct colors. Digital technology and COVID-19 are all associated with the blue cluster. Cloud computing, hospital, and algorithm IOTs represent green clusters - finally, the purple cluster healthcare system, algorithm, and security. In the following part, each cluster is further investigated to find the finch services.

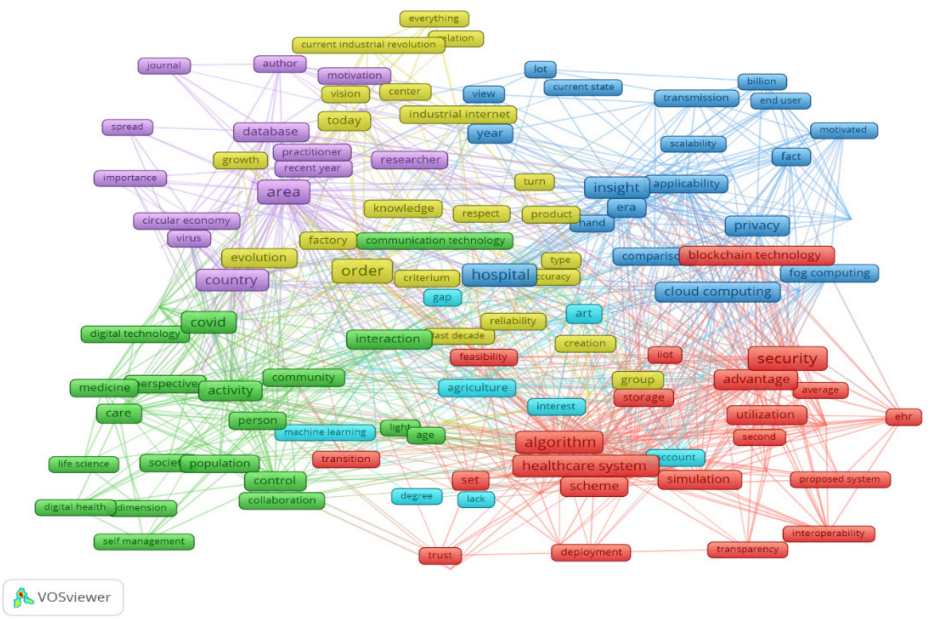

Fig. 4. The classification of literature using the VOS viewer 


\subsection{Healthcare system}

The healthcare sector evolved from 1.0 to 4.0 , where healthcare 1.0 was the more significant the doctor oriented, and Healthcare 2.0 substituted instruction manual records with an electronic healthcare record (EHRs). Healthcare 3.0 was patient-centric, and Healthcare 4.0 manages cloud computing (CC), fog computing (F.C.), Internet of things (IoT), and telehealthcare technologies available to share data between the various stakeholders [8]. Setting up a safe and secure procedure for healthcare 4.0 has always been a difficult task. Collaboration between doctors is improved, as health care professionals can efficiently come together, organize their events, share their information about the patients, and guarantee to deliver the best-synchronized care [9]. According to [10], medication 4.0 has brought about an enhanced attempt to build the platform, both on the hardware level in Addition to the underlying software point. Such a vision has resulted in the development of healthcare IoT (H-IoT) methods. The fundamental facilitating technologies consist of the interaction systems sandwiched between the detecting nodules and the CPUs and the processing procedures for producing a production from the data gathered by the devices. These devices continuously measure, progress, detain, and store biometric data such as body position, weight, and movements, sleep quality, blood pressure, blood oxygen saturation, body temperature, heart rhythm and rate, blood oxygen, fatigue levels, and respiration rate [11].

However, some challenges remain in the framework of primary health systems, such as exchanging electronic health records, but have yet to be fixed [12]. According to [13], breakthroughs in blockchain technology have improved transactions involving medical records, insurance billing, and smart contracts, permitting permanent access to and security of data while still providing a distributed database of transactions. Blockchain technologies and considerable data involvement enhance the abilities of the healthcare system in recent times. Big data has the potential to support a variety of medicinal and healthcare operations, including disease control and patient care. Big data is a large amount of data saved due to enhancements in various cloud computing and wireless communication technologies [14]. Focus On the identified issues, the Internet is a backbone for delay mitigation using $5 \mathrm{G}$ networks for future ultra-reliable low-latency applications such as Healthcare 4.0, Business 4.0, virtual world and artificial intelligence, and intelligent education [15]. The healthcare system in industry 4.0 is mainly dependent on digital technologies, and high-speed Internet is bringing changes with effectiveness in the healthcare system. The old, dated technologies are now fully cloud computing-centric in recent times. Table 2 is showing the details of the author, segment, and settings for the research.

Table 2. Details of authors, citations, classification, segment, and settings

\begin{tabular}{|l|c|l|l|l|}
\hline \multicolumn{1}{|c|}{ Authors } & Cited by & Classification & \multicolumn{1}{c|}{ Segment } & \multicolumn{1}{c|}{ Settings } \\
\hline Tanwar et al., [13] & 112 & $\begin{array}{l}\text { Healthcare } \\
\text { Systems }\end{array}$ & Blockchain Technology & medical records \\
\hline Aceto et al., [9] & 74 & $\begin{array}{l}\text { Healthcare } \\
\text { Systems }\end{array}$ & $\begin{array}{l}\text { Information and } \\
\text { Communication } \\
\text { Technologies (ICTs) }\end{array}$ & Industry 4.0 paradigm \\
\hline
\end{tabular}

(Continued) 
Table 2. Details of authors, citations, classification, segment, and settings (continued)

\begin{tabular}{|l|c|l|l|l|}
\hline \multicolumn{1}{|c|}{ Authors } & Cited by & Classification & \multicolumn{1}{c|}{ Segment } & \multicolumn{1}{c|}{ Settings } \\
\hline Qadri et al., [10] & 67 & $\begin{array}{l}\text { Healthcare } \\
\text { Systems }\end{array}$ & Medicine 4.0 & artificial Intelligence (A.I.) \\
\hline Gupta et al., [8] & 42 & $\begin{array}{l}\text { Healthcare } \\
\text { Systems }\end{array}$ & Healthcare 4.0 & Industry 4.0 \\
\hline Dautov et al., [11] & 27 & $\begin{array}{l}\text { Healthcare } \\
\text { Systems }\end{array}$ & Internet of Things (IoT) & Healthcare Industry 4.0 \\
\hline Sannino et al., [15] & 15 & $\begin{array}{l}\text { Healthcare } \\
\text { Systems }\end{array}$ & $\begin{array}{l}\text { Internet of things } \\
\text { technologies }\end{array}$ & photoplethysmography \\
\hline Larrucea et al., [12] & 14 & $\begin{array}{l}\text { Healthcare } \\
\text { Systems }\end{array}$ & Patients' data & $\begin{array}{l}\text { Healthcare Industry } \\
\text { architecture }\end{array}$ \\
\hline Elhoseny et al., [14] & 113 & $\begin{array}{l}\text { Healthcare } \\
\text { System }\end{array}$ & Internet of Things (IoT) & $\begin{array}{l}\text { virtual machines selection } \\
\text { (V.M.s) }\end{array}$ \\
\hline
\end{tabular}

\subsection{Cloud computing}

Industry 4.0 is defined by creative technological solutions that provide tools for achieving a new working platform that humans and devices can communicate while benefiting from self-organizing and optimizing real-time [16]. According to [17] Instead, Healthcare 4.0 is defined by the adoption of three major paradigms: the Internet of Things, Big Data, and Cloud Computing, which are revolutionizing eHealth and its entire ecosystem in the same way that Industry 4.0 is revolutionizing the manufacturing sector. The rapid adoption and evolution of cloud/edge computing, Internet of Things (IoT), and big data technologies are transforming eHealth and the entire Industry 4.0 in healthcare applications [18]. Healthcare Industry 4.0 allows for increased productivity, Flexibility in various areas, including production and speed. Both manufacturing and market processes are improved product quality and productivity and changing business models by altering interactions with the value chain and competitors and customers [19]. The edge computing framework has piqued many people's attention in recent years as a viable alternative to traditional cloud-based approaches for reducing interaction timing and the massive amount of data flowing from the Internet of Things (IoT) devices to the Internet [20].

According to several academics, Edge Computing collects computers, devices, and network resources that generate and collect data and send it to remote data centers in the cloud. The works of these researchers depict Edge Computing from a variety of perspectives, including frameworks, skills, software technologies, and characteristics [21]. The Cloud-centric execution of IoT applications barely meets such requirements because Cloud datacentres are located several hops away from IoT devices. Fog computing, a Cloud at the Edge network extension, can run these applications closer to data sources. As a result, fog computing can improve application service delivery time while avoiding network congestion [20]. Traditional healthcare is transforming into virtual, distributed care that heavily relies on cutting-edge technologies such as artificial intelligence (A.I.), deep learning, data analytics, genomics, home-based healthcare, robotics, and $3 \mathrm{D}$ printing of tissue and implants. In the future, fundamental shifts will reshape 
the healthcare industry [22]. The study of [23] concluded that every nation's global news is dominated by Industry 4.0, which is ushering in the fourth generation of industrialization. Digitalization is an essential factor in this process, and the prospects of Augmented Reality (A.R.) and Virtual Reality (V.R.) are closely monitored by various business houses from all sectors around the world. Cloud technologies are enhancing the healthcare system's abilities and patient care [24]. Many advancements in technology nations are evolving healthcare infrastructure using these technologies under IR 4.0. Table 3 is showing the details of the authors, citations, segments, and settings.

Table 3. Details of authors, citations, classification, segment, and settings

\begin{tabular}{|c|c|c|c|c|}
\hline Authors & Cited by & Classification & Segment & Settings \\
\hline Aceto et al., [17] & 90 & $\begin{array}{l}\text { Cloud } \\
\text { computing }\end{array}$ & $\begin{array}{l}\text { Cloud and Fog } \\
\text { Computing }\end{array}$ & $\begin{array}{l}\text { Industry } 4.0 \\
\text { technologies }\end{array}$ \\
\hline Sittón-Candanedo et al., [21] & 49 & $\begin{array}{l}\text { Cloud } \\
\text { computing }\end{array}$ & Edge Computing & $\begin{array}{l}\text { IoT (Internet of } \\
\text { Things) devices }\end{array}$ \\
\hline (Roy et al., 2019) [19] & 36 & $\begin{array}{l}\text { Cloud } \\
\text { computing }\end{array}$ & $\begin{array}{l}\text { Mobile cloud } \\
\text { computing }\end{array}$ & $\begin{array}{l}\text { healthcare } \\
\text { applications }\end{array}$ \\
\hline Pace et al., [20] & 18 & $\begin{array}{l}\text { Cloud } \\
\text { computing }\end{array}$ & edge network & $\begin{array}{l}\text { Internet of Things } \\
\text { (IoT) }\end{array}$ \\
\hline Wehde, [22] & 11 & $\begin{array}{l}\text { Cloud } \\
\text { computing }\end{array}$ & Virtual & healthcare industry \\
\hline Stillings, [23] & 9 & $\begin{array}{l}\text { Cloud } \\
\text { computing }\end{array}$ & $\begin{array}{l}\text { Augmented Reality } \\
\text { (A.R.) and Virtual } \\
\text { Reality (V.R.) }\end{array}$ & learning mechanism \\
\hline Pieroni et al., [16] & 5 & $\begin{array}{l}\text { Cloud } \\
\text { computing }\end{array}$ & Industry 4.0 & $\begin{array}{l}\text { manufacturing to } \\
\text { healthcare }\end{array}$ \\
\hline
\end{tabular}

\subsection{Digital technologies and COVID-19}

The COVID 19 pandemic has increased demand for essential healthcare materials and medicines and the need for advanced information technology applications. For addressing the numerous problems associated with this viral pandemic, various advanced technologies must be introduced. Industry 4.0 consists of advanced healthcare and information technologies used to meet the customized needs of various human beings in less time [25]. According to [26], during the COVID-19 pandemic, disruptive technologies reduce the burden on the healthcare team. Innovative devices can be used to monitor patients infected with COVID-19. For COVID-19, public health organizations recommend that disruptive technologies play a critical role in public health. Industry 4.0 technologies offer an intelligent solution to complex services and care. Using these technologies, organizations can create a better hospital management system and make human life more comfortable by reducing errors in the treatment process. So, this allows for quick and much more real-time assessment, as well as minor irritation throughout the entire testing process [27]. During the COID-19 pandemic, technologies play a vital role in detecting the suspects of virus transmission. Initially, it was difficult for healthcare professionals and many healthcare professionals. Digital technologies create an atmosphere secure for healthcare workers [28]. Mobile applications, robots, Wi-Fi cameras, scanners, and drones are used to control 
the transmission of the virus. Industry 4.0 influenced digital technologies' significant contribution to pandemic control [29].

However, Hospitals deployed a complete automation system/platform for accessing healthcare services because of the deep convergence of automation technologies and health informatics driven by Industry 4.0. Mainly, online appointment services can be accessed directly from the Internet by using an automation booking device, a mobile app, or a permitted platform. It has dramatically facilitated the lives of young patients who are adept at using the Internet [30]. According to [31], healthcare 4.0 is a relatively new term derived from Industry 4.0. Innovative health, mHealth (mobile health), wireless health, eHealth, online health, medical I.T., telehealth/telemedicine, digital medicine, health informatics, pervasive health, and health information systems are examples of data-driven digital health technologies in healthcare 4.0. That influenced the fourth paradigm, which is data-intensive technological innovation. It also discusses digital frontiers and disruptive technologies propelling new business opportunities and value chains in the healthcare industry. Digital technologies are equally effective for young and adults' health perspectives. New business models for delivering healthcare, behavior support, and health information via social media are driven by technology and consumer behavior [32]. This new situation has the potential to increase patient safety. Before they can effectively incorporate social media into their business model, businesses must achieve certain levels of knowledge, sophistication, and social media strategy integration [33]. Table 4 is showing the details of the authors, citations, segments, and settings.

Table 4. Details of authors, citations, classification, segment, and settings

\begin{tabular}{|l|c|l|l|l|}
\hline \multicolumn{1}{|c|}{ Authors } & Cited by & \multicolumn{1}{|c|}{ Classification } & \multicolumn{1}{c|}{ Segment } & \multicolumn{1}{c|}{ Settings } \\
\hline Jayaraman et al., [31] & 12 & $\begin{array}{l}\text { Digital } \\
\text { technologies }\end{array}$ & Healthcare 4.0 & $\begin{array}{l}\text { Health Care } \\
\text { Application }\end{array}$ \\
\hline Xie et al., [30] & 9 & $\begin{array}{l}\text { Digital } \\
\text { technologies }\end{array}$ & Hospitals & Mobile healthcare \\
\hline Thomas \& Woodside, [33] & 7 & $\begin{array}{l}\text { Digital } \\
\text { technologies }\end{array}$ & Social media & applications \\
\hline Javaid, et al., [25] & 134 & COVID-19 & Digital technologies & Industry 4.0 \\
\hline Abdel-Basset et al., [26] & 18 & COVID-19 & $\begin{array}{l}\text { Disruptive } \\
\text { technologies }\end{array}$ & Technologies \\
\hline Mustapha et al., [32] & 18 & COVID-19 & Industry 4.0 & Industry 4.0 \\
\hline Javaid, et al., [27] & 14 & COVID-19 & $\begin{array}{l}\text { Industry 5.0 } \\
\text { technologies }\end{array}$ & Monitoring system \\
\hline Chauhan et al., [29] & 5 & COVID-19 & hospitals & Healthcare \\
\hline
\end{tabular}

\section{Conclusion}

To ensure the future of humanity's social system as we know it, several significant problems that will take time to solve, such as reducing carbon footprint, improving healthcare for an aging population, and discovering innovative and sustainable food and 
energy resources, must be addressed (Griffiths \& Ooi, 2018). The keywords "Industry 4.0 AND healthcare" were decided to enter the search bar for the early extracting data. The literature was chosen systematically to avoid duplication and irrelevant records. The Preferred Reporting Items for Systematic Reviews and Meta-Analyses (PRISMA) create the plan of what data should have been included and excluded from systematic reviews and meta-analyses. The primary data is derived from Scopus. The filtration method is the same, and the data is finally merged on a single Microsoft Excel sheet. The present study classifies the healthcare facilities reported in the literature as being influenced by Industry 4.0. Researchers cover various topics, including Industrial Internet, digital technologies, healthcare systems, healthcare 4.0, and cloud computing. Used For categorization of literature, the author's keywords and VOS viewer results yield the same results. The VOS viewer was used for data mining in the current study. We also count the number of times the terms appear together to identify fintech-related literature. Figure 5 is showing the outcomes of industry 4.0 and the healthcare system.

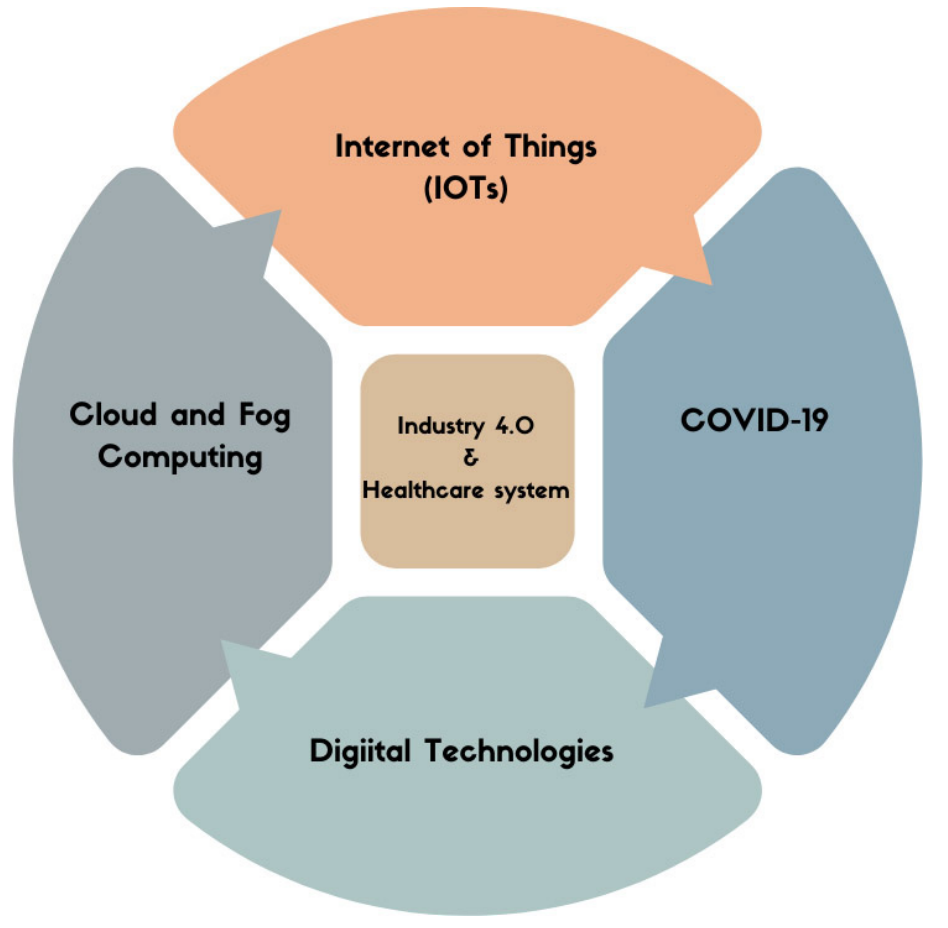

Fig. 5. Outcomes of the industry 4.0 and healthcare system

The research aimed to evaluate the impact of Industry 4.0 on the healthcare system. The three initial categories identified from the literature, healthcare system, cloud computing, COVID-19, and digital technologies. The research related to healthcare significantly emphasizing on utilization of technologies to make secure human civilization. The growing phase of digital technologies received massive attention from researchers 
in recent years [34]. In Addition, industry 4.0 is enhancing the healthcare system due to the large-scale influence of clouding and the industrial Internet. The technologies largely influence the future of humanity, and human involvement is decreasing down. Industry 4.0 improves the lifestyle of societies.

\section{References}

[1] J. A. G. de M. e. C. E Melo and N. M. F. Araújo, "Impact of the fourth industrial revolution on the health sector: A qualitative study," Healthc. Inform. Res., vol. 26, no. 4, pp. 328-334, 2020, doi: https://doi.org/10.4258/hir.2020.26.4.328

[2] M. I. Qureshi, N. Khan, S. M. Ahmad Hassan Gillani, and H. Raza, "A systematic review of past decade of mobile learning: What we learned and where to go," Int. J. Interact. Mob. Technol., vol. 14, no. 6, pp. 67-81, Apr. 2020, doi: https://doi.org/10.3991/ijim.v14i06.13479

[3] N. Mohamed and J. Al-Jaroodi, "The impact of industry 4.0 on healthcare system engineering," Apr. 2019, doi: https://doi.org/10.1109/SYSCON.2019.8836715

[4] S. Zeadally and O. Bello, "Harnessing the power of Internet of Things based connectivity to improve healthcare," Internet of Things, vol. 14, p. 100074, Jun. 2021, doi: https://doi. org/10.1016/j.iot.2019.100074

[5] A. A. Siyal, A. Z. Junejo, M. Zawish, K. Ahmed, A. Khalil, and G. Soursou, "Applications of blockchain technology in medicine and healthcare: Challenges and future perspectives," Cryptography, vol. 3, no. 1, pp. 1-16, Mar. 2019, doi: https://doi.org/10.3390/ cryptography 3010003

[6] K. Hartley and D. S. L. Jarvis, "Policymaking in a low-trust state: legitimacy, state capacity, and responses to COVID-19 in Hong Kong," Policy Soc., vol. 39, no. 3, pp. 403-423, Jul. 2020, doi: https://doi.org/10.1080/14494035.2020.1783791

[7] H. Kondylakis et al., "COVID-19 Mobile apps: A systematic review of the literature," Journal of Medical Internet Research, vol. 22, no. 12. JMIR Publications Inc., p. e23170, Dec. 2020, doi: https://doi.org/10.2196/23170

[8] R. Gupta, S. Tanwar, S. Tyagi, and N. Kumar, "Tactile internet and its applications in 5G era: A comprehensive review,” Int. J. Commun. Syst., vol. 32, no. 14, p. e3981, Sep. 2019, doi: https://doi.org/10.1002/dac.3981

[9] G. Aceto, V. Persico, and A. Pescapé, "The role of Information and Communication Technologies in healthcare: taxonomies, perspectives, and challenges," Journal of Network and Computer Applications, vol. 107. Academic Press, pp. 125-154, Apr. 2018, doi: https:// doi.org/10.1016/j.jnca.2018.02.008

[10] Y. A. Qadri, A. Nauman, Y. Bin Zikria, A. V. Vasilakos, and S. W. Kim, "The Future of Healthcare Internet of Things: A Survey of Emerging Technologies," IEEE Communications Surveys and Tutorials, vol. 22, no. 2. Institute of Electrical and Electronics Engineers Inc., pp. 1121-1167, Apr. 2020, doi: https://doi.org/10.1109/COMST.2020.2973314

[11] R. Dautov, S. Distefano, and R. Buyya, "Hierarchical data fusion for Smart Healthcare," J. Big Data, vol. 6, no. 1, pp. 1-23, Dec. 2019, doi: https://doi.org/10.1186/s40537-019-0183-6

[12] X. Larrucea, M. Moffie, S. Asaf, and I. Santamaria, "Towards a GDPR compliant way to secure European cross border Healthcare Industry 4.0," Comput. Stand. Interfaces, vol. 69, p. 103408, Mar. 2020, doi: https://doi.org/10.1016/j.csi.2019.103408

[13] S. Tanwar, K. Parekh, and R. Evans, "Blockchain-based electronic healthcare record system for healthcare 4.0 applications," J. Inf. Secur. Appl., vol. 50, p. 102407, Feb. 2020, doi: https://doi.org/10.1016/j.jisa.2019.102407 
[14] M. Elhoseny, A. Abdelaziz, A. S. Salama, A. M. Riad, K. Muhammad, and A. K. Sangaiah, "A hybrid model of Internet of Things and cloud computing to manage big data in health services applications," Futur. Gener. Comput. Syst., vol. 86, pp. 1383-1394, Sep. 2018, doi: https://doi.org/10.1016/j.future.2018.03.005

[15] G. Sannino, I. De Falco, and G. De Pietro, "A Continuous Noninvasive Arterial Pressure (CNAP) Approach for Health 4.0 Systems," IEEE Trans. Ind. Informatics, vol. 15, no. 1, pp. 498-506, Jan. 2019, doi: https://doi.org/10.1109/TII.2018.2832081

[16] A. Pieroni, N. Scarpato, and M. Brilli, "Performance study in autonomous and connected vehicles a industry 4.0 issue,” J. Theor. Appl. Inf. Technol., vol. 96, no. 4, pp. 984-994, 2018.

[17] G. Aceto, V. Persico, and A. Pescapé, "Industry 4.0 and Health: Internet of Things, Big Data, and Cloud Computing for Healthcare 4.0," Journal of Industrial Information Integration, vol. 18. 2020, doi: https://doi.org/10.1016/j.jii.2020.100129

[18] N. Khan and M. I. Qureshi, "A systematic literature review on online medical services in Malaysia," Int. J. online Biomed. Eng., vol. 16, no. 6, pp. 107-118, 2020, doi: https://doi .org/10.3991/ijoe.v16i06.13573

[19] S. Roy, A. K. Das, S. Chatterjee, N. Kumar, S. Chattopadhyay, and J. J. P. C. Rodrigues, "Provably Secure Fine-Grained Data Access Control over Multiple Cloud Servers in Mobile Cloud Computing Based Healthcare Applications," IEEE Trans. Ind. Informatics, vol. 15, no. 1, pp. 457-468, Jan. 2019, doi: https://doi.org/10.1109/TII.2018.2824815

[20] P. Pace, G. Aloi, R. Gravina, G. Caliciuri, G. Fortino, and A. Liotta, "An Edge-Based Architecture to Support Efficient Applications for Healthcare Industry 4.0," IEEE Trans. Ind. Informatics, vol. 15, no. 1, pp. 481-489, Jan. 2019, doi: https://doi.org/10.1109/ TII.2018.2843169

[21] I. Sittón-Candanedo, R. S. Alonso, J. M. Corchado, S. Rodríguez-González, and R. Casado-Vara, "A review of edge computing reference architectures and a new global edge proposal," Futur. Gener. Comput. Syst., vol. 99, pp. 278-294, Oct. 2019, doi: https://doi .org/10.1016/i.future.2019.04.016

[22] M. Wehde, "Healthcare 4.0," IEEE Eng. Manag. Rev., vol. 47, no. 3, pp. 24-28, Jul. 2019, doi: https://doi.org/10.1109/EMR.2019.2930702

[23] C. Stillings, "Digital Transformation in Plastics Industry: From Digitization Toward Virtual Material,"SpringerCham.pp.287-298,2020,https://doi.org/10.1007/978-3-030-41309-5_19

[24] M. I. Qureshi, N. Khan, H. Raza, A. Imran, and F. Ismail, "Digital Technologies in Education 4.0. Does it Enhance the Effectiveness of Learning? A Systematic Literature Review.," Int. J. Interact. Mob. Technol., vol. 15, no. 4, 2021. https://doi.org/10.3991/ijim.v15i04.20291

[25] M. Javaid, A. Haleem, R. Vaishya, S. Bahl, R. Suman, and A. Vaish, "Industry 4.0 technologies and their applications in fighting COVID-19 pandemic," Diabetes Metab. Syndr. Clin. Res. Rev., vol. 14, no. 4, pp. 419-422, Jul. 2020, doi: https://doi.org/10.1016/j dsx.2020.04.032

[26] M. Abdel-Basset, V. Chang, and N. A. Nabeeh, "An intelligent framework using disruptive technologies for COVID-19 analysis," Technol. Forecast. Soc. Change, vol. 163, p. 120431, Feb. 2021, doi: https://doi.org/10.1016/j.techfore.2020.120431

[27] M. Javaid, A. Haleem, R. P. Singh, M. I. U1 Haq, A. Raina, and R. Suman, "Industry 5.0: Potential applications in covid-19," J. Ind. Integr. Manag., vol. 5, no. 4, pp. 507-530, Dec. 2020, doi: https://doi.org/10.1142/S2424862220500220

[28] M. Shamim Kaiser et al., "IWorksafe: Towards Healthy Workplaces during COVID-19 with an Intelligent Phealth App for Industrial Settings," IEEE Access, vol. 9, pp. 13814-13828, 2021, doi: https://doi.org/10.1109/ACCESS.2021.3050193

[29] A. Chauhan, S. K. Jakhar, and C. Chauhan, "The interplay of circular economy with industry 4.0 enabled smart city drivers of healthcare waste disposal," J. Clean. Prod., vol. 279, 2021, doi: https://doi.org/10.1016/j.jclepro.2020.123854 
[30] C. Xie, H. Cai, Y. Yang, L. Jiang, and P. Yang, "User Profiling in Elderly Healthcare Services in China: Scalper Detection," IEEE J. Biomed. Heal. Informatics, vol. 22, no. 6, pp. 1796-1806, Nov. 2018, doi: https://doi.org/10.1109/JBHI.2018.2852495

[31] P. P. Jayaraman, A. R. M. Forkan, A. Morshed, P. D. Haghighi, and Y. Bin Kang, "Healthcare 4.0: A review of frontiers in digital health," Wiley Interdisciplinary Reviews: Data Mining and Knowledge Discovery, vol. 10, no. 2. Wiley-Blackwell, p. e1350, Mar. 2020, doi: https://doi.org/10.1002/widm.1350.

[32] I. Mustapha, N. Thuy Van, M. Shahverdi, M. I. Qureshi, and N. Khan, "Effectiveness of Digital Technology in Education During COVID-19 Pandemic. A Bibliometric Analysis," Int. J. Interact. Mob. Technol., vol. 15, no. 08, p. 136, Apr. 2021, doi: https://doi.org/10.3991/ ijim.v15i08.20415

[33] L. Thomas and J. M. Woodside, "Social media maturity model," Int. J. Healthc. Manag., vol. 9, no. 1, pp. 67-73, Jan. 2016, doi: https://doi.org/10.1080/20479700.2015.1101940

[34] L. Hughes, Y. K. Dwivedi, S. K. Misra, N. P. Rana, V. Raghavan, and V. Akella, "Blockchain research, practice and policy: Applications, benefits, limitations, emerging research themes and research agenda," Int. J. Inf. Manage., vol. 49, pp. 114-129, Dec. 2019, doi: https://doi .org/10.1016/j.ijinfomgt.2019.02.005

\section{Authors}

Ishamuddin Mustapha, Faculty of Technology Management and Technopreneurship, Universiti Teknikal Malaysia Melaka, Malaysia. E-mail: Ishamuddin@unikl.

Nohman Khan, UniKL Business School, Universiti Kuala Lumpur, Malaysia. E-mail: nohman.khan@s.unikl.edu.my.

Muhammad Imran Qureshi, Faculty of Technology Management and Technopreneurship, Universiti Teknikal Malaysia Melaka, Malaysia.E-mail: qureshi@utem.edu.my.

Ahmad Ali Harasis, Department of Business Administration, Middle East University, Amman 11831, Jordan.

Nguyen Thuy Van, Faculty of Social Sciences and Humanities, Universiti Teknologi Malaysia. E-mail: thuyvannguyen@utm.my.

Article submitted 2021-07-15. Resubmitted 2021-08-24. Final acceptance 2021-08-26. Final version published as submitted by the authors. 